PR-28

\title{
SYNTHESIS, STRUCTURAL ELUCIDATION AND BIOASSAY OF MORPHOLINE/THIOMORPHOLINE AND PIPERIDINE CONTAINING OXAZOLES
}

\author{
G. Sravya, ${ }^{1}$ N. Bakthavatchala Reddy, ${ }^{1}$ and Grigory V Zyryanov ${ }^{1,2}$ \\ ${ }^{1}$ Chemical Engineering Institute, Ural Federal University, Yekaterinburg 620002, Russia. \\ ${ }^{2}$ I. Ya. Postovsky Institute of Organic Synthesis, Ural Division of Russian Academy of Sciences, 22 S. \\ Kovalevskoy St., 620219, Yekaterinburg, Russian Federation. \\ E-mail: sravyasvu@gmail.com
}

\begin{abstract}
The ubiquity of azoles in a wide variety of naturally occurring and synthetic molecules and their pivotal role as synthetic intermediates has attracted the attention of both industrial and academic communities. Oxazoles are widely distributed in natural products including phenoxan,hennoxazoles and many of them possess significant biological activities such as antifungal, cytotoxic, anthelmintic etc., Methods for the synthesis of substituted oxazoles include Robinson - Gabriel synthesis of cyclodehydration of $\alpha$-acylaminocarbonyl compounds, Morpholine is a heterocyclic organic compound, has both features of amine due to the presence of nitrogen atom that it considered as a secondary amine and also ether functional group due to the presence of oxygen atom. Moreover, thiomorpholines analogs are associated with a variety of pharmacological activities including anti mycobacterial, antibacterial, analgesic and anti-inflammatory. Similarly, the piperazine moiety is existing in numerous biologically active compounds as well as the antimicrobial and the antidepressants. In continuation of our studies and also to establish structureactivity relationship of the compounds, the present work synthesis and antimicrobial activity of sulfonyl methyl linked mono and bis-heterocycles having different heterocyclic moieties has been taken up.

\section{References}

1. Shaw A. Y. Ugi/Robinson-Gabriel reactions directed toward the synthesis of 2,4,5-trisubstituted oxazoles / Z. Xu, C. Hulme // Tetrahedron Letters.- 2012. - Vol.53. Iss. 15. - P.1998-2000.

2. Williams D. R. Studies of mild dehydrogenations in heterocyclic systems / P. D. Lowder, Y. G. Gu. D. A. Brooks // Tetrahedron Letters. - 1997. - Vol.38, Iss. 3. - P. 331-334.

3. Baran, Y. Spectroscopic and structural properties of N-(acetamide)morpholinium bromide. H. Ozay, H. Esener, M. Turkyilmaz // Spectrochimica Acta Part A: Molecular and Biomolecular Spectroscopy. - 2011 - Vol.81. Iss. - 1. P.99-103.
\end{abstract}

